\title{
An Employment Intervention Program (Work2Prevent) for Young Men Who Have Sex With Men and Transgender Youth of Color (Phase 2): Protocol for a Single-Arm Mixed Methods Pilot Test to Assess Feasibility and Acceptability
}

Brandon J Hill ${ }^{1}$, PhD; Darnell N Motley ${ }^{2}$, PhD; Kris Rosentel ${ }^{2}$, MA; Alicia VandeVusse ${ }^{3}$, PhD; Robert Garofalo ${ }^{4}$, MD, MPH; John A Schneider ${ }^{5}$, MD, MPH; Lisa M Kuhns ${ }^{4}$, PhD, MPH; Michele D Kipke ${ }^{6}$, PhD; Sari Reisner ${ }^{7}, \mathrm{ScD}$; Betty M Rupp ${ }^{8}$, MPH; Maria Sanchez ${ }^{8}$, BS; Micah McCumber ${ }^{8}$, MS; Laura Renshaw ${ }^{8}$, BS; Rachel West Goolsby ${ }^{8}$, BA; Matthew Shane Loop ${ }^{8}$, PhD

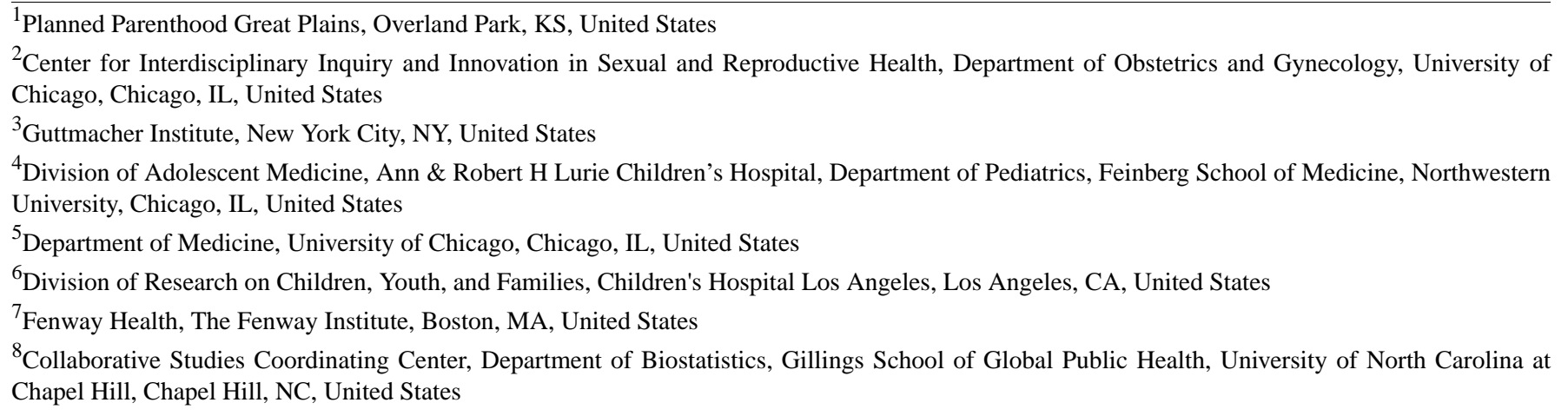

\section{Corresponding Author:}

Brandon J Hill, PhD

Planned Parenthood Great Plains

$4401 \mathrm{~W}$ 109th St \#100

Overland Park, KS,

United States

Phone: 19133454624

Email: brandon.hill@ppgreatplains.org

\begin{abstract}
Background: Young cisgender men who have sex with men (YMSM), young transgender women (YTW), and gender nonconforming (GNC) youth of color face substantial economic and health disparities. In particular, HIV risk and infection among these groups remains a significant public health issue. In 2017, $17 \%$ of all new HIV diagnoses were attributed to male-to-male sexual contact among adolescents and young adults aged 13 to 24 years. However, such disparities cannot be attributed to individual-level factors alone but rather are situated within larger social and structural contexts that marginalize and predispose YMSM, YTW, and GNC youth of color to increased HIV exposure. Addressing social and structural risk factors requires intervention on distal drivers of HIV risk, including employment and economic stability. The Work2Prevent (W2P) study aims to target economic stability through job readiness and employment as a structural-level intervention for preventing adolescent and young adult HIV among black and Latinx YMSM, YTW, and GNC youth. This study seeks to assess intervention feasibility and acceptability in the target populations and determine preliminary efficacy of the intervention to increase employment and reduce sexual risk behaviors.
\end{abstract}

Objective: The goal of the research is to pilot-test a tailored, theoretically informed employment intervention program among YMSM, YTW, and GNC youth of color. This intervention was adapted from Increased Individual Income and Independence, an existing evidence-based employment program for HIV-positive adults during phase 1 of the W2P study.

Methods: The employment intervention will be pilot-tested among vulnerable YMSM, YTW, and GNC youth of color in a single-arm pre-post trial to assess feasibility, acceptability, and preliminary estimates of efficacy. 
Results: Research activities began in March 2018 and were completed in November 2019. Overall, 5 participants were enrolled in the pretest and 51 participants were enrolled in the pilot.

Conclusions: Interventions that address the social and structural drivers of HIV exposure and infection are sorely needed in order to successfully bend the curve in the adolescent and young adult HIV epidemic. Employment as prevention has the potential to be a scalable intervention that can be deployed among this group.

Trial Registration: ClinicalTrials.gov NCT03313310; https://clinicaltrials.gov/ct2/show/NCT03313310

International Registered Report Identifier (IRRID)： DERR1-10.2196/16401

(JMIR Res Protoc 2020;9(8):e16401) doi: 10.2196/16401

\section{KEYWORDS}

HIV/AIDS; YMSM; YTW; GNC youth; LGBTQ; unemployment; homelessness; sex work

\section{Introduction}

\section{Background}

Youth assigned male at birth who have male sexual partners, including young cisgender men who have sex with men (YMSM), young transgender women (YTW), and gender nonconforming (GNC) youth, face substantial economic and health disparities. In particular, HIV risk and infection among YMSM, YTW, and GNC youth remains a significant public health problem. In the United States, YMSM, YTW, and GNC youth experience high rates of HIV infection [1,2]. In 2017, $17 \%$ of all new HIV diagnoses were attributed to male-to-male sexual contact among adolescents and young adults aged 13 to 24 years [1]. Additionally, 75\% of adolescent and young adult HIV diagnoses were among black and Latinx individuals [1]. Epidemiological HIV estimates for transgender populations are limited due to a lack of existing data. However, a meta-analysis of US studies involving trans women found an average HIV prevalence rate of $14 \%$ across studies that included laboratory testing [2]. In this meta-analysis, prevalence rates were higher among black trans women at $44 \%$ [2].

However, these disparities cannot be understood solely in the context of individual-level risk behavior given that there are multiple social and structural factors that increase risk for HIV exposure and acquisition among YMSM, YTW, and GNC youth of color [3-10]. Despite advancements in lesbian, gay, bisexual, transgender, and queer (LGBTQ) rights, LGBTQ people face persistent stigma, discrimination, and victimization in school, the workplace, housing, and health care [11-14]. Such inequities are met with limited legal protections as few state laws specifically protect LBGTQ people. The consequences of this discrimination and lack of protections may be particularly pronounced for LGBTQ people of color, who face intersectional forms of discrimination and structural marginalization; a high proportion of YMSM, YTW, and GNC youth of color live in poverty; experience high rates of homelessness, unemployment, and violence; and have limited access to HIV and other health and human services [14-20].

Furthermore, these experiences of social and economic marginalization contribute to increased risk for HIV exposure and infection through their impacts on social determinants of health (eg, availability of pre-exposure prophylaxis [PrEP] providers in the community) as well as coping and survival behaviors (eg, substance use, sex work) [14-16,18,20]. In particular, financial insecurity and socioeconomic disconnection may increase engagement with survival sex work or sex in exchange for money, drugs, food, and housing among YMSM, YTW, and GNC youth of color [21-23]. Engagement with survival sex work can place these individuals at heightened risk for HIV and sexully transmitted diseases (STIs) by increasing exposure to higher prevalence sexual networks, increasing their number of sexual partners, and presenting challenges to negotiating condom use [21-23].

Structural-level interventions have the potential to increase agency in members of marginalized groups and can facilitate health-positive actions that benefit the individual and the community [24]. Often focused on distal drivers of poor health, structural-level interventions can promote uptake of health-positive behaviors and improve access to health-promotive environments [24,25]. Given the ways that economic instability may place YMSM, YTW, and GNC youth of color at higher risk for HIV acquisition, structural intervention to promote economic stability may serve to allow these youth to enact health-promoting behaviors. Accordingly, employment as prevention has the potential to be a scalable intervention that can be deployed among this group. Phase 1 of this study has already been published [26].

\section{Rationale for Employment as HIV Prevention}

Faced with few economic options and protections, YMSM, YTW, and GNC youth of color may migrate to nontraditional economies or unregulated work as a means of survival. In a study conducted by Adolescent Medicine Trials Network for HIV/AIDS Interventions (ATN) members in Los Angeles and Chicago, $76 \%$ of 151 YTW aged 15 to 24 years reported engaging in sex work, with $35 \%$ in the past 3 months [5]. Among HIV-positive YTW of color living in Washington, DC, $23 \%$ were involved in sex work-underscoring the link between adolescent and young adult sex work and HIV exposure [27]. In a large US study of YMSM $(\mathrm{N}=3316$, median age 19 years $)$, roughly $12 \%$ reported engaging in sex work in the past 6 months [28]. Sex work and HIV risk are further complicated by drug and alcohol abuse [16]. In order to effectively target economic stability as a route toward reducing HIV risk, there is an acute need for scalable, low-cost but potentially high impact structural-level interventions that address the distal drivers of economic marginalization and adolescent and young adult HIV infection $[24,25,29,30]$. The objective of the Work2Prevent (W2P) study is to adapt and pilot-test Increased Individual 
Income and Independence (iFOUR), an effective, theoretically driven employment program for HIV-positive adults [31-34] to the needs of vulnerable YMSM, YTW, and GNC youth of color aged 16 to 24 years.

\section{Theoretical Framework}

The iFOUR intervention draws on the theoretical framework of the health belief model (HBM) [35], a widely used expectancy value model of health behavior change, and the conceptual framework of supported employment (SE), a model in which individuals with physical or intellectual disabilities or impairments, mental health issues, or chronic conditions are assisted with identifying their own capabilities and obtaining employment [36,37]. The objective of the iFOUR intervention is to help HIV-positive individuals identify barriers to obtaining employment, increase the perceived benefits of employment, and assess perceptions of the severity of their illness in order to increase behavioral intentions and self-efficacy for employment. Further, iFOUR participants gain the tools and skills needed to effectively seek, secure, and maintain employment and increase economic independence and stability [31-34].

In order to adapt and tailor the iFOUR intervention to the needs of adolescents and young adults of color, the intervention draws on positive youth development (PYD) in which young people understand, value, and develop external and internal assets such as community support, empowerment to act, clear boundaries, constructive use of time, commitment to learning, positive self-concept, and social and emotional competency [38-40]. PYD approaches orient young people toward future goals, develop the skills necessary to engage youth in real-world roles and activities, and build or fortify young peoples' relationships with social networks [40]. PYD builds from resiliency research in assuming that all youth are capable of achieving positive health outcomes despite challenges they may face in their environment [38]. The adapted intervention will draw on PYD to provide the support, relationship-building skills, and increased social and emotional competency shown to help youth succeed in employment.

\section{Methods}

\section{Conceptual Model}

The W2P conceptual model shown in Figure 1 draws on the existing iFOUR theoretical framework to hypothesize the potential relationship between adolescent and young adult employment and HIV risk. The W2P model proposes that employment and subsequent economic connection and stability serve as a structural-level intervention for HIV prevention among adolescents and young adults. The hypothesis is that the adapted and tailored iFOUR intervention will facilitate increased job self-efficacy and job readiness (path A) and ultimately increase employment placement and maintenance (path B). Further, establishing economic stability will decrease engagement in HIV risk behaviors, increase HIV prevention and care (path C), and decrease involvement with known social determinants of HIV such as sex work and substance use (path D), which are directly linked to HIV transmission and acquisition among YMSM, YTW, and GNC youth of color (paths $\mathrm{E}$ and $\mathrm{F}$ ).

Figure 1. Conceptual model.

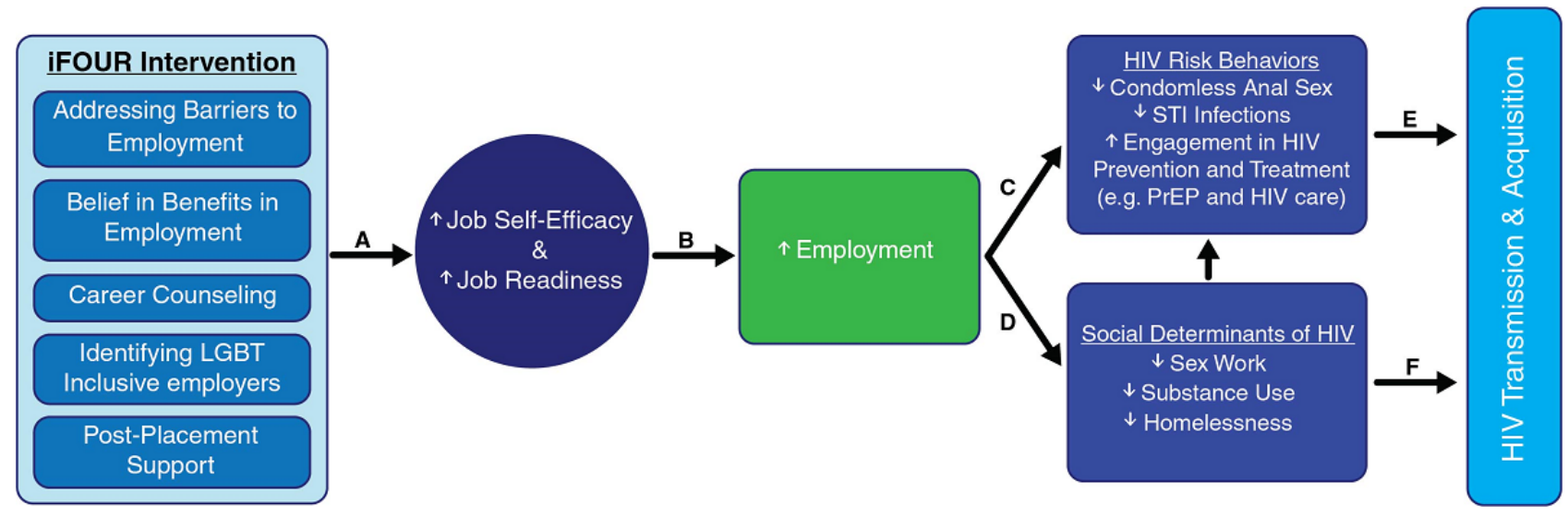

\section{Study Design}

W2P uses a mixed-methods design. Phase 1 involves the adaptation of relevant intervention components from the existing evidence-based iFOUR employment program for HIV-positive adults [31-34] to YMSM, YTW, and GNC youth of color. Phase 2 , the topic of this paper, consists of pretesting the intervention and study assessments and then running a single-arm pilot test of the adapted intervention to assess feasibility and acceptability with YMSM, YTW, and GNC youth of color, as well as provide preliminary estimates of efficacy using pre-post comparisons.

\section{Ethics, Consent, and Institutional Board Approval}

W2P has been reviewed and approved by the University of Chicago institutional review board (IRB\# 16-1152). Informed consent for this study is obtained in person by study staff before any study-related activities take place.

\section{Participants and Study Setting}

Study participants include up to 75 black or African American and Hispanic or Latinx YMSM, YTW, and GNC youth. Inclusion criteria include (1) being assigned male at birth, (2) reporting ever having sex with men, (3) identifying as African American or black or Hispanic or Latinx, (4) aged 16 to 24 years, (5) self-report HIV negative or unknown status, (6) 
English-speaking, (7) currently unemployed but seeking employment or employed only part-time, defined as working 35 hours or less on average per week, and (8) able to attend a 4-session workshop. All study visits are conducted at the University of Chicago Center for Interdisciplinary Inquiry and Innovation in Sexual and Reproductive Health (Ci3).

\section{Recruitment}

Planned participant recruitment efforts include the distribution and posting of printed materials such as flyers, hand bills, and branded merchandise; online postings on websites and social media such as Facebook and Twitter; advertisements such as Chicago Transit Authority posters; and chats through the mobile app Jack'd. Study staff will also actively recruit from primary clinics serving YMSM, YTW, and GNC youth such as Howard
Brown Health during their youth drop-in programs and at local gathering places and events frequented by the target population such as night clubs, LGBTQ centers, House \& Ball events, Black Pride events, Pride Fest, and community outreach HIV testing events. Interested participants complete a prescreen survey to assess eligibility. All interested participants are contacted and informed whether they are eligible. Eligible and interested participants are scheduled for baseline study visits.

\section{Visit Schedule and Data Collection}

W2P consists of data collection across 3 time points, at baseline, postintervention, and 8-month postintervention, as referenced in Table 1. A 4-session intervention workshop series occurs between the first and second time points.

Table 1. Study procedures.

\begin{tabular}{llll}
\hline Study procedures & Baseline & Intervention & Postintervention \\
\hline HIV/STI $^{\mathrm{a}}$ testing & $\mathrm{x}$ & $\mathrm{x}$ \\
Substance use screening & $\mathrm{x}$ & $\mathrm{x}$ & $\mathrm{x}$ \\
ACASI survey & $\mathrm{x}$ & $\mathrm{x}$ & $\mathrm{x}$ \\
Workshop sessions (4) & & follow-up & \\
\hline
\end{tabular}

${ }^{\mathrm{a}} \mathrm{STI}$ : sexually transmitted disease.

${ }^{\mathrm{b}}$ ACASI: audio computer-assisted self-interview.

\section{Incentives}

Study participants are offered compensation for their time. Pretest participants may receive up to US \$260 total, while pilot-test participants may receive up to US \$330 total for complete participation. Participants will receive US $\$ 30$ for each study visit, completed at baseline, postintervention, and 8-month follow-up, up to US $\$ 40$ for biological specimens at baseline and 8-month follow-up, if provided, and US $\$ 40$ for each workshop session attended. Payment is provided in the form of cash or Visa gift card equivalent.

\section{Pretest}

Up to 5 participants will be recruited for a pretest of the baseline study visit, the 4-session workshop series, and the postintervention study visit. Pretest participants will not complete the follow-up assessment. The purpose of the pretest is to give study staff an opportunity to familiarize themselves with the study visit procedures and workshop curriculum. The pretest will also allow staff to determine if any final adjustments to procedures, study instruments, or the curriculum are needed prior to full rollout of the pilot testing. Participants who enroll in the pretest are not eligible to participate in the phase 2 pilot.

\section{Baseline}

Participants will complete informed consent, confirm eligibility, and then complete an audio computer-assisted self-interview (ACASI) survey using an iPad. Survey items include questions pertaining to demographics, sexual behaviors, HIV-risk behaviors, relationships, employment, income, substance use, and other structural variables such as homelessness, food insecurity, and health care use. Optional biologic samples will be collected from participants who consent to them. These samples include a finger stick for rapid HIV testing using the Determine HIV-1/2 Ag/Ab Combo (Abbott); a urine sample for drug screening, chlamydia, and gonorrhea testing; and anal and oral swabs for chlamydia and gonorrhea testing.

\section{Intervention}

Participants complete a 4-session intervention workshop adapted from the existing iFOUR program [31-33]. Session 1 focuses on goal setting and identifying strengths; session 2 on communication, networking, and job searching; session 3 on balancing work with health and wellness; and session 4 on preparing job application materials and interview preparation. This adaptation of the curriculum was informed by interviews and focus groups with the target population as well as feedback from a youth advisory board. The protocol for conducting interviews and focus groups is published elsewhere [26].

Workshops sessions are delivered by two facilitators in groups of 6 to 12 participants across the course of 2 weeks with 2 sessions per week. The W2P Career Readiness Workbook is used as a guide for all workshop sessions and is given to all study participants at the first session. Facilitators use an annotated W2P Facilitator Guide that provides detailed instruction on delivery of the intervention curriculum. During each session, facilitators complete a fidelity assessment to help ensure fidelity to the W2P Career Readiness Workbook and after each session complete a workshop debriefing form to capture any workshop notes or comments. 


\section{Postintervention}

Once participants complete the workshop sessions, participants complete a postintervention ACASI survey using an iPad. Survey items include questions on workshop evaluation, job-seeking self-efficacy, and PrEP and HIV testing use.

\section{Month 8 Follow-Up}

The final study visit occurs 8 months after the intervention has been completed. During this visit, participants complete the baseline ACASI survey using an iPad and provide repeat biologic samples if they consented to them.

\section{Outcomes}

\section{Primary Outcomes}

\section{Information Systems Success Model Score}

The Information Systems Success Model (ISSM) will be used to assess for intervention acceptability and satisfaction. The 21-item scale yields a total score and measures 4 subdomains: information quality, handbook quality, perceived usefulness, and overall satisfaction. This scale has been adapted from Horvath et al [41].

\section{Workshop Completion}

Workshop completion will be used to assess intervention feasibility. Workshop or intervention completion is defined as having attended at least 2 of the 4 workshop sessions and is measured by tracking participant attendance.

\section{Change in Job-Seeking Self-Efficacy Scale Score}

Job-seeking self-efficacy is defined as one's perceived ability and confidence to perform job search and application activities. The 12-item Job-Seeking Self-Efficacy scale by Barlow et al [42] yields a total score where higher values indicate higher self-efficacy. Job-seeking self-efficacy has been found to be associated with employment in a previous study of transgender women of color [29].

\section{Change in Protean Career Attitudes Scale Score}

Protean career attitudes (PCAs) are defined as having self-direction in the pursuit of success in one's work. PCAs have previously been found to be associated with positive career satisfaction and self-perceived success [43]. The validated 7-item scale by Porter et al [44] yields a total score and measures 2 subdomains: self-directed attitudes and values-driven attitudes.

\section{Secondary Outcomes}

\section{Change in Self-Reported Hours Worked per Week}

Hours worked per week is self-reported at baseline and at the 8-month follow-up visit. Change in hours worked per week from the baseline to the 8-month follow-up will be used to assess change in employment status.

\section{Change in Self-Reported Sexual Risk Behaviors}

Sexual risk behaviors are defined as self-reported engagement in the following behaviors during the previous 6 months [45]:

- Condomless anal intercourse (receptive or insertive) with cisgender male partner of unknown HIV status
- Anal intercourse (receptive or insertive) with 3 or more cisgender males

- Sex with cisgender male partner with an STI

- Condomless anal intercourse (receptive or insertive) with $\mathrm{HIV}+$ cisgender male partner

- Anal intercourse (receptive or insertive) with condom failure

- Transactional sex work involvement

The previous 6 months refers to the 6 months prior to the baseline visit for the first assessment and the 6 months prior to the 8-month follow-up visit for the second assessment. Change in sexual risk behaviors will be defined as the change in self-reported behaviors from baseline to the 8-month follow-up.

\section{Change in Chlamydia Test Result}

Prevalence of chlamydia infections will be assessed at baseline and 8-month follow-up using oral, anal, and urine samples. Each of the 3 tests yields a positive or negative result. Change in chlamydia test result will be defined as the change from baseline to the 8-month follow-up. Oral, anal, and urine tests are treated as separate outcomes.

\section{Change in Gonorrhea Test Result}

Prevalence of gonorrhea infections will be assessed at baseline and 8-month follow-up using oral, anal, and urine samples. Each of the 3 tests yields a positive or negative result. Change in gonorrhea test result will be defined as the change from baseline to the 8-month follow-up. Oral, anal, and urine tests are treated as separate outcomes.

\section{Reactive HIV Test}

Testing for reactive or nonreactive HIV will be assessed at baseline and 8-month follow-up. The reactive HIV test outcome uses the 8-month follow-up result.

\section{Power}

Given the exploratory nature of this study and limited access to this population, the analyses are not designed to have a specified level of statistical power. A repeated measures pre and post design is used to reduce the variability in the estimate of the treatment effect.

\section{Statistical Analysis}

Descriptive statistics will be used to analyze the proportions and central tendencies for participant sociodemographic characteristics collected in the surveys. We will first generate frequencies, means, and other measures of central tendency as appropriate to describe our sample and outcomes at each of the 3 time points: baseline, postintervention, and 8-month follow-up.

All participants who are enrolled at baseline and complete the baseline ACASI will be included in the primary and secondary analyses as applicable. Analysis population participants will be included in all primary and secondary analyses for which their data for the specified outcome are not missing. Participants who do not attend any workshop sessions will not be included in analyses involving workshop evaluation. Primary analyses will assess intervention acceptability, satisfaction, and feasibility as well as change in job-seeking self-efficacy and PCA score. Secondary analyses will evaluate the intervention by comparing employment and sexual risk behaviors pre- and postintervention. 
Changes in primary and secondary outcomes between baseline and 8-month follow-up will be assessed using paired $t$ tests for continuous variables (eg, ISSM, job-seeking self-efficacy, and PCA scores) and the McNemar test for matched categorical variables (eg, STI results). We will use standard diagnostic tools to assess the appropriateness of the normality assumption and, if approximate normality of the residuals is not tenable, a nonparametric test for continuous paired data (ie, Wilcoxon sign-rank test) will be used. All hypothesis testing will be performed at an alpha level of 0.10 , given the exploratory nature of the study. To the extent that data allows, multivariable analyses will adjust for sociodemographic characteristics, workshop attendance, baseline employment status, and study completeness. Analytical models will include linear regression or generalized linear models for continuous outcomes and logistic regression for binary outcomes.

Analysis of the primary and secondary outcomes are described in detail within the statistical analysis plan, which will be accessible on ClinicalTrials.gov once study results have been entered.

\section{Results}

Phase 2 W2P research activities began in March 2018 and were completed in November 2019. Overall, 5 participants were enrolled in the pretest, and 51 participants were enrolled in the pilot.

\section{Discussion}

The goal of this project is to pilot-test W2P, a structural-level employment intervention for YMSM, YTW, and GNC youth of color. Interventions that address the social and structural drivers of HIV exposure and infection are sorely needed in order to successfully bend the curve in the adolescent and young adult HIV epidemic. Although important for HIV prevention, few individual interventions consider the complex ecological factors that make YMSM, YTW, and GNC youth of color vulnerable to HIV. Thus, engagement with individual-level interventions, such as PrEP adherence and consistent condom use, may be impeded by broader issues such as homelessness, unemployment, and survival sex work. Addressing these factors is an important first step in mitigating risk for adolescent and young adult HIV.

Although employment is an important target for increasing economic stability and decreasing reliance on nontraditional economies such as survival sex work, one limitation of this protocol may be that an immediate individual reduction of HIV exposure may not be detectable. Often structural-level interventions rely on measurement of predictive outcomes that ultimately have downstream effects on health outcomes. To address this challenge, the study focuses on measures of job readiness, job-seeking self-efficacy, and career readiness as the strongest predictors of employment engagement and employability. Follow-up occurs at 8 months postintervention allowing participants time to enact skills and behaviors gained from the employment intervention. Additionally, there is a potential limitation that the results of the intervention may not be generalizable beyond urban YMSM, YTW, and GNC youth of color, as both the formative phase and intervention tailoring and refinement focused on the needs of this population. Subsequent adaptation and refinement may be necessary to engage youth outside of this target population.

If W2P demonstrates feasibility and acceptability among YMSM, YTW, and GNC youth of color in this pilot study, we plan to test the efficacy of the intervention in a multicity longitudinal trial across the ATN study sites. If W2P demonstrates efficacy, this intervention will provide vulnerable youth a tailored youth-focused way to gain employment and life-based skills necessary to achieve economic stability and ultimately reduce the propensity for HIV exposure and infection.

\section{Acknowledgments}

This study is supported by the ATN from the National Institutes of Health (5U24HD089880-02) through the Eunice Kennedy Shriver National Institute of Child Health and Human Development (B Kapogiannis and S Lee), National Institute on Minority Health and Health Disparities, National Institute of Mental Health, and National Institute on Drug Abuse. Network operations and data management are supported through the ATN Coordinating Center at the University of North Carolina at Chapel Hill. The content in this manuscript is solely the responsibility of the authors and does not necessarily represent the official views of the National Institutes of Health.

Author AV's affiliation is included for informational purposes only; this work was not conducted under the auspices of the Guttmacher Institute. The views expressed herein are those of the authors and do not necessarily reflect the views of the Guttmacher Institute.

\section{Conflicts of Interest}

None declared.

\section{Multimedia Appendix 1}

Peer review report with comments.

[DOCX File, $20 \mathrm{~KB}$-Multimedia Appendix 1]

\section{References}


1. HIV Surveillance Report, 2017. Atlanta: Division of HIV/AIDS Prevention, National Center for HIV/AIDS, Viral Hepatitis, STD, and TB Prevention; 2018 Nov. URL: https://www.cdc.gov/hiv/pdf/library/reports/surveillance/ cdc-hiv-surveillance-report-2017-vol-29.pdf [accessed 2019-11-19]

2. Becasen JS, Denard CL, Mullins MM, Higa DH, Sipe TA. Estimating the prevalence of HIV and sexual behaviors among the US transgender population: a systematic review and meta-analysis, 2006-2017. Am J Public Health 2019 Jan;109(1):e1-e8. [doi: 10.2105/AJPH.2018.304727] [Medline: 30496000]

3. Baral SD, Poteat T, Strömdahl S, Wirtz AL, Guadamuz TE, Beyrer C. Worldwide burden of HIV in transgender women: a systematic review and meta-analysis. The Lancet Infectious Diseases 2013 Mar;13(3):214-222. [doi: 10.1016/S1473-3099(12)70315-8] [Medline: 23260128]

4. Bauer GR, Travers R, Scanlon K, Coleman TA. High heterogeneity of HIV-related sexual risk among transgender people in Ontario, Canada: a province-wide respondent-driven sampling survey. BMC Public Health 2012 Apr 20;12(1):292 [FREE Full text] [doi: 10.1186/1471-2458-12-292] [Medline: 22520027]

5. Brennan J, Kuhns LM, Johnson AK, Belzer M, Wilson EC, Garofalo R, Adolescent Medicine Trials Network for HIV/AIDS Interventions. Syndemic theory and HIV-related risk among young transgender women: the role of multiple, co-occurring health problems and social marginalization. Am J Public Health 2012 Sep;102(9):1751-1757 [FREE Full text] [doi: 10.2105/AJPH.2011.300433] [Medline: 22873480]

6. Garofalo R, Osmer E, Sullivan C, Doll M, Harper G. Environmental, psychosocial, and individual correlates of HIV risk in ethnic minority male-to-female transgender youth. J HIV/AIDS Prev Child Youth 2007 May 15;7(2):89-104. [doi: 10.1300/J499v07n02_06]

7. Graham R, Berkowitz B, Blum R, Bockting W, Bradford J, de Vries B, et al. The health of lesbian, gay, bisexual, and transgender people: building a foundation for better understanding. Washington: Institute of Medicine; 2011 Mar 31. URL: http://www.nationalacademies.org/hmd/Reports/2011/The-Health-of-lesbian-gay-bisexual-and-transgender-people.aspx [accessed 2019-11-19]

8. Maulsby C, Millett G, Lindsey K, Kelley R, Johnson K, Montoya D, et al. HIV among black men who have sex with men (MSM) in the United States: a review of the literature. AIDS Behav 2014 Jan;18(1):10-25. [doi: 10.1007/s10461-013-0476-2] [Medline: 23620241]

9. Millett GA, Flores SA, Peterson JL, Bakeman R. Explaining disparities in HIV infection among black and white men who have sex with men: a meta-analysis of HIV risk behaviors. AIDS 2007 Oct 01;21(15):2083-2091. [doi:

10.1097/QAD.0b013e3282e9a64b] [Medline: $\underline{\text { 17885299] }}$

10. Operario D, Nemoto T. HIV in transgender communities: syndemic dynamics and a need for multicomponent interventions. J Acquir Immune Defic Syndr 2010 Dec;55 Suppl 2:S91-S93 [FREE Full text] [doi: 10.1097/QAI.0b013e3181fbc9ec] [Medline: 21406995]

11. Kosciw JG, Palmer NA, Kull RM, Greytak EA. The effect of negative school climate on academic outcomes for LGBT youth and the role of in-school supports. J School Violence 2013 Jan;12(1):45-63. [doi: 10.1080/15388220.2012.732546]

12. Melendez RM, Exner TA, Ehrhardt AA, Dodge B, Remien RH, Rotheram-Borus MJ, et al. Health and health care among male-to-female transgender persons who are HIV positive. Am J Public Health 2006 Jun;96(6):1034-1037. [doi: 10.2105/AJPH.2004.042010] [Medline: 16131645]

13. Pizer J, Sears B, Mallory C, Hunter N. Evidence of persistent and pervasive workplace discrimination against LGBT people: the need for federal legislation prohibiting discrimination and providing for equal employment benefits. Loyola of Los Angeles Law Review. 2012 Jan. URL: https://williamsinstitute.law.ucla.edu/wp-content/uploads/ Pizer-Mallory-Sears-Hunter-ENDA-LLR-2012.pdf [accessed 2019-12-11]

14. Santos GM, Wilson EC, Rapues J, Macias O, Packer T, Raymond HF. HIV treatment cascade among transgender women in a San Francisco respondent driven sampling study. Sex Transm Infect 2014 Aug;90(5):430-433. [doi: 10.1136/sextrans-2013-051342] [Medline: 24714446]

15. Bradford J, Reisner SL, Honnold JA, Xavier J. Experiences of transgender-related discrimination and implications for health: results from the Virginia Transgender Health Initiative Study. Am J Public Health 2013 Oct;103(10):1820-1829. [doi: 10.2105/AJPH.2012.300796] [Medline: 23153142]

16. Gayles TA, Kuhns LM, Kwon S, Mustanski B, Garofalo R. Socioeconomic disconnection as a risk factor for increased HIV infection in young men who have sex with men. LGBT Health 2016 Jun;3(3):219-224 [FREE Full text] [doi: 10.1089/lgbt.2015.0102] [Medline: 27002852]

17. Mena L, Crosby RA, Geter A. A novel measure of poverty and its association with elevated sexual risk behavior among young Black MSM. Int J STD AIDS 2017 May;28(6):602-607. [doi: 10.1177/0956462416659420] [Medline: 27389778]

18. Meyer IH. Prejudice, social stress, and mental health in lesbian, gay, and bisexual populations: conceptual issues and research evidence. Psychol Bull 2003 Sep;129(5):674-697 [FREE Full text] [doi: 10.1037/0033-2909.129.5.674] [Medline: 12956539]

19. Rosentel K, VandeVusse A, Hill BJ. Racial and socioeconomic inequity in the spatial distribution of LGBTQ human services: an exploratory analysis of LGBTQ services in Chicago. Sex Res Soc Policy 2020 Mar 17:87-103. [doi: 10.1007/s13178-019-0374-0] 
20. Sevelius JM, Patouhas E, Keatley JG, Johnson MO. Barriers and facilitators to engagement and retention in care among transgender women living with human immunodeficiency virus. Ann Behav Med 2014 Feb;47(1):5-16 [FREE Full text] [doi: 10.1007/s12160-013-9565-8] [Medline: 24317955]

21. Operario D, Soma T, Underhill K. Sex work and HIV status among transgender women: systematic review and meta-analysis. J Acquir Immune Defic Syndr 2008 May 01;48(1):97-103. [doi: 10.1097/QAI.0b013e31816e3971] [Medline: 18344875]

22. Poteat T, Wirtz AL, Radix A, Borquez A, Silva-Santisteban A, Deutsch MB, et al. HIV risk and preventive interventions in transgender women sex workers. The Lancet 2015 Jan 17;385(9964):274-286 [FREE Full text] [doi: 10.1016/S0140-6736(14)60833-3] [Medline: 25059941]

23. Williams ML, Atkinson J, Klovdahl A, Ross MW, Timpson S. Spatial bridging in a network of drug-using male sex workers. J Urban Health 2005 Mar;82(1 Suppl 1):i35-i42 [FREE Full text] [doi: 10.1093/jurban/jti022] [Medline: 15738322]

24. Auerbach JD, Parkhurst JO, Cáceres CF. Addressing social drivers of HIV/AIDS for the long-term response: conceptual and methodological considerations. Glob Public Health 2011;6 Suppl 3:S293-S309. [doi: 10.1080/17441692.2011.594451] [Medline: 21745027]

25. Seeley J, Watts CH, Kippax S, Russell S, Heise L, Whiteside A. Addressing the structural drivers of HIV: a luxury or necessity for programmes? J Int AIDS Soc 2012;15 Suppl 1:1-4 [FREE Full text] [doi: 10.7448/IAS.15.3.17397] [Medline: 22905346]

26. Hill BJ, Motley DN, Rosentel K, VandeVusse A, Garofalo R, Schneider JA, et al. An Employment Intervention Program (Work2Prevent) for Young Men Who Have Sex With Men and Transgender Youth of Color (Phase 1): Protocol for Determining Essential Intervention Components Using Qualitative Interviews and Focus Groups. JMIR Research Protocols 2020 (forthcoming). [doi: 10.2196/16384]

27. Xavier JM, Bobbin M, Singer B, Budd E. A needs assessment of transgendered people of color living in Washington, DC. Int J Transgenderism 2005 Oct 11;8(2-3):31-47. [doi: 10.1300/J485v08n02_04]

28. Harawa NT, Greenland S, Bingham TA, Johnson DF, Cochran SD, Cunningham WE, et al. Associations of race/ethnicity with HIV prevalence and HIV-related behaviors among young men who have sex with men in 7 urban centers in the United States. J Acquir Immune Defic Syndr 2004 Apr 15;35(5):526-536. [doi: 10.1097/00126334-200404150-00011] [Medline: $\underline{15021318]}$

29. Hill BJ, Rosentel K, Bak T, Silverman M, Crosby R, Salazar L, et al. Exploring individual and structural factors associated with employment among young transgender women of color using a no-cost transgender legal resource center. Transgend Health 2017 Mar;2(1):29-34 [FREE Full text] [doi: 10.1089/trgh.2016.0034] [Medline: 28795154]

30. Kammerer N, Mason T, Connors M, Durkee R. Transgender health and social service needs in the context of HIV risk. In: Bockting W, editor. Transgender and HIV: Risks, Prevention, and Care. New York: Haworth Press; 2001:39-57.

31. Colaric S. Employment best practices \& support systems. Chicago House \& Social Service Agency. 2012 Dec 03. URL: https://vimeo.com/54802313 [accessed 2019-07-25]

32. US Department of Housing and Urban Development. Implementing the national HIV/AIDS strategy: a report to the White House Office of National Aids Policy. 2011 Feb. URL: https://files.hiv.gov/s3fs-public/nhas-operational-plan-hud.pdf [accessed 2019-07-25]

33. Perloff J, Potts C. iFOUR employment program: increase individual income and independence. 2011 Presented at: Positive Futures Pre-Conference Institute for the United States Conference on AIDS; 2011; Chicago URL: http://www. workingpositive.net/pdf/pf2011 ifour.pdf

34. Razzano LA, Hamilton MM, Yost C, Pashka NJ, Perloff JK. Employment outcomes for individuals with HIV/AIDS and co-occurring mental health factors. Am J Psychiatr Rehabil 2015 Jan 02;18(1):19-41. [doi: 10.1080/15487768.2015.1001700]

35. Becker MH. The Health Belief Model And Personal Health Behavior. Thorofare: Slack; 1974.

36. O'Brien J. Working on...a survey of emerging issues in supported employment for people with severe disabilities. Syracuse: Center on Human Policy; 1990. URL: https://eric.ed.gov/?id=ED336919 [accessed 2019-07-29]

37. Pashka N, Razzano L. A new look at supported employment: modernizing evidence-based practices. 2013 Presented at: NAMI Illinois State Conference; 2013; Chicago URL: https://images.slideplayer.com/23/6901818/slides/slide_1.jpg

38. Bernat DH, Resnick MD. Healthy youth development: science and strategies. J Public Health Manag Pract 2006 Nov;12 Supp 6:S10-SS6. [doi: 10.1097/00124784-200611001-00004] [Medline: 17035894]

39. Bowers EP, von Eye A, Lerner JV, Arbeit MR, Weiner MB, Chase P, et al. The role of ecological assets in positive and problematic developmental trajectories. J Adolesc 2011 Dec;34(6):1151-1165. [doi: 10.1016/j.adolescence.2011.07.007] [Medline: 22118508]

40. Gavin LE, Catalano RF, David-Ferdon C, Gloppen KM, Markham CM. A review of positive youth development programs that promote adolescent sexual and reproductive health. J Adolesc Health 2010 Mar;46(3 Suppl):S75-S91. [doi: 10.1016/j.jadohealth.2009.11.215] [Medline: 20172462]

41. Horvath KJ, Oakes JM, Rosser BRS, Danilenko G, Vezina H, Amico KR, et al. Feasibility, acceptability and preliminary efficacy of an online peer-to-peer social support ART adherence intervention. AIDS Behav 2013 Jul;17(6):2031-2044 [FREE Full text] [doi: 10.1007/s10461-013-0469-1] [Medline: 23553347] 
42. Barlow J, Wright C, Cullen L. A job-seeking self-efficacy scale for people with physical disabilities: Preliminary development and psychometric testing. British Journal of Guidance \& Counselling 2002 Feb;30(1):37-53. [doi: $10.1080 / 030698880220106500]$

43. Volmer J, Spurk D. Protean and boundaryless career attitudes: relationships with subjective and objective career success. ZAF 2011 Jan;43(3):207-218. [doi: 10.1007/s12651-010-0037-3]

44. Porter C, Woo SE, Tak J. Developing and validating short form protean and boundaryless career attitudes scales. J Career Assess 2015 Jan 06;24(1):162-181. [doi: 10.1177/1069072714565775]

45. Hosek SG, Rudy B, Landovitz R, Kapogiannis B, Siberry G, Rutledge B, Adolescent Trials Network (ATN) for HIVAIDS Interventions. An HIV preexposure prophylaxis demonstration project and safety study for young MSM. J Acquir Immune Defic Syndr 2016 Dec 31;74(1):21-29 [FREE Full text] [doi: 10.1097/QAI.0000000000001179] [Medline: 27632233]

\author{
Abbreviations \\ ACASI: audio computer-assisted self-interview \\ ATN: Adolescent Medicine Trials Network for HIV/AIDS Interventions \\ Ci3: Center for Interdisciplinary Inquiry and Innovation in Sexual and Reproductive Health \\ GNC: gender nonconforming \\ HBM: health belief model \\ iFOUR: Increased Individual Income and Independence \\ ISSM: Information Systems Success Model \\ LGBTQ: lesbian, gay, bisexual, transgender, queer \\ PCA: protean career attitudes \\ PrEP: pre-exposure prophylaxis \\ PYD: positive youth development \\ SE: supported employment \\ STI: sexually transmitted disease \\ W2P: Work2Prevent study \\ YMSM: young men who have sex with men \\ YTW: young transgender women
}

Edited by S Allison, I Holloway, B Mustanski, A Pettifor, R Schnall; submitted 25.09.19; peer-reviewed by V McMahan, T Poteat;
comments to author 11.11.19; revised version received 22.11.19; accepted 29.11.19; published 10.08.20
Please cite as:
Hill BJ, Motley DN, Rosentel K, VandeVusse A, Garofalo R, Schneider JA, Kuhns LM, Kipke MD, Reisner S, Rupp BM, Sanchez, M,
McCumber M, Renshaw L, West Goolsby R, Loop MS
An Employment Intervention Program (Work2Prevent) for Young Men Who Have Sex With Men and Transgender Youth of Color
(Phase 2): Protocol for a Single-Arm Mixed Methods Pilot Test to Assess Feasibility and Acceptability
JMIR Res Protoc 2020;9(8):e16401
URL: https://www.researchprotocols.org/2020/8/e16401
doi: $10.2196 / 16401$
PMID: $\underline{32773376}$

CBrandon J Hill, Darnell N Motley, Kris Rosentel, Alicia VandeVusse, Robert Garofalo, John A Schneider, Lisa M Kuhns, Michele D Kipke, Sari Reisner, Betty M Rupp, Maria Sanchez, Micah McCumber, Laura Renshaw, Rachel West Goolsby, Matthew Shane Loop. Originally published in JMIR Research Protocols (http://www.researchprotocols.org), 10.08.2020. This is an open-access article distributed under the terms of the Creative Commons Attribution License (https://creativecommons.org/licenses/by/4.0/), which permits unrestricted use, distribution, and reproduction in any medium, provided the original work, first published in JMIR Research Protocols, is properly cited. The complete bibliographic information, a link to the original publication on http://www.researchprotocols.org, as well as this copyright and license information must be included. 